\title{
STRATEGI PENGEMBANGAN OBYEK WISATA DI TAMAN WISATA ALAM TELAGA WARNA
}

\section{(Tourism Object Development Strategy in Taman Wisata Alam Telaga Warna)}

\author{
Meri Juanda ${ }^{1}$, Ina Lidiawati ${ }^{2}$, Abdul Rahman Rusli ${ }^{3}$ \\ ${ }^{1}$ Balai Besar Taman Nasional Gunung Gede Pangrango \\ Jl.Raya Cibodas, Cipanas-Cianjur \\ email : eriejuan05@yahoo.co.id \\ ${ }^{2}$ Fakultas Kehutanan, Universitas Nusa Bangsa \\ Jl. KH. Sholeh Iskandar Km. 4, Tanah Sareal - Bogor 16166, Indonesia \\ email : inalidiawati@gmail.com \\ ${ }^{3}$ Fakultas Kehutanan, Universitas Nusa Bangsa \\ J1. KH. Sholeh Iskandar Km. 4, Tanah Sareal - Bogor 16166, Indonesia \\ email : rusli.abdulrahman@unb.ac.id
}

Correspondent author : rusli.abdulrahman@unb.ac.id

\begin{abstract}
TWA Telaga Warna is a Nature Conservation Area which is mainly intended for tourism and nature recreation. TWA Potential of Telaga Warna is not yet known with certainty, given its intangible nature and has recently experienced a decrease in the number of visitors. For this reason, it is necessary to know the potential and strategies for developing tourism objects in TWA Telaga Warna. The method used in this research is based on the analysis of the area of operation of the object of natural tourist attraction (ADO - ODTWA), the index of the feasibility of an object and the analysis of strengths, weaknesses, opportunities and threats (SWOT). Based on the research, it was found that TWA Telaga Warna has potential tourism objects that are worth developing $(77.55 \%)$ and the TWA Telaga Warna development strategy is the SO strategy, namely maximizing the strength (strength) owned and maximizing the opportunity (opportunity) by preserving the natural good flora., fauna, natural beauty and water availability of TWA Telaga Warna are the satisfaction of visitors, making infrastructure so that visitors can enjoy natural panoramas and easy access to information, and making tour packages at TWA Telaga Warna in collaboration with the hotel.
\end{abstract}

Keywords : Strategy, Development, Tourism Site, TWA Telaga Warna

\begin{abstract}
ABSTRAK
TWA Telaga Warna adalah salah satu jenis Kawasan Pelestarian Alam. TWA Telaga Warna mempunyai pemanfaatan utama untuk pariwisata dan rekreasi alam. TWA Potensi Telaga Warna hingga saat ini belum diketahui secara pasti, mengingat sifatnya yang tidak nyata (intangible) dan belakangan ini mengalami penurunan jumlah pengunjung. Untuk itu perlu diketahui potensi dan strategi Pengembangan Objek Wisata di TWA Telaga Warna. Metode yang digunakan dalam penelitian ini didasarkan pada Analisis Daerah Operasi Objek Daya Tarik Wisata Alam (ADO - ODTWA), dalam indeks kelayakan suatu obyek dan Analisis Strenghts, Weaknesses, Opportunities and Threats (SWOT). Berdasarkan hasil penelitian diperoleh bahwa TWA Telaga warna memiliki potensi obyek wisata yang layak dikembangkan $(77,55 \%)$ dan strategi pengembangan TWA Telaga Warna yaitu dengan strategi SO yaitu memaksimalkan kekuatan (strength) yang dimiliki dan memaksimalkan peluang (opportunity) dengan menjaga kelestarian alam baik flora, fauna, keindahan alamnya dan ketersedian air TWA Telaga Warna, menjadi kepuasan pengunjung, membuat sarana prasarana agar pengunjung dapat menikmati panorama alam dan akses informasi yang mudah, dan membuat paket perjalanan wisata di TWA Telaga Warna dengan bekerjasama pihak hotel.
\end{abstract}

Kata kunci : Strategi, pengembangan, obyek wisata, TWA Telaga Warna 


\section{PENDAHUluan}

UU No.5 Tahun 1990 dan UU No. 41 tahun 1999 menyatakan bahwa Taman Wisata Alam (TWA) adalah kawasan pelestarian alam yang terutama dimanfaatkan untuk pariwisata dan rekreasi alam. TWA memiliki fungsi pelestarian (melindungi sistem penyangga kehidupan bagi daerah sekitarnya); fungsi akademis (tempat pendidikan alam dan pengembangan ilmu pengetahuan); serta fungsi pariwisata (tujuan wisata dan rekreasi alam yang didukung oleh keindahan alam dan ekosistem kawasan).

TWA Telaga Warna yang terletak di jalur puncak Kabupaten Bogor merupakan salah satu Kawasan yang menjadi destinasi wisata pilihan. Kawasan ini memiliki potensi wisata berupa danau, panorama alam bukit, flora dan fauna, dan sumber mata air. Seiring dengan perkembangan industri pariwisata, persaingan dalam meningkatkan jumlah kunjungan menjadi tidak terhindarkan. Demikian pula dengan TWA Telaga Warna yang mengalami penurunan jumlah kunjungan.

Fenomena penurunan pengunjung perlu diantisipasi dengan pemahaman terhadap strategi pengelolaan yang lebih baik di masa mendatang. Berdasarkan hal itulah penelitian ini perlu dilakukan. Penelitian ini bertujuan mengetahui potensi wisata dan strategi pengembangan yang paling tepat untuk diterapkan di TWA Telaga Warna.

\section{METODE PENELITIAN}

Penelitian dilakukan di TWA Telaga Warna. Secara administratif, kawasan ini berada di Kecamatan Cisarua, Kabupaten Bogor, Provinsi Jawa Barat. Pengambilan data dilakukan pada April - Mei 2019.

Alat dan bahan yang digunakan dalam penelitian ini adalah peta lokasi, kamera, alat tulis, dan aplikasi pemetaan (Arc. GIS, Google Maps dan lain - lain).

Sampel pengunjung ditentukan dengan teknik random sampling. Sedangkan untuk pengelola, sampel ditentukan menggunakan teknik purposive sampling yang telah disesuaikan dengan kebutuhan penelitian. Sampel pengunjung TWA Telaga Warna menggunakan rumus Slovin (Priyono, 2016).

$$
n=\frac{N}{N(d)^{2}+1}
$$

Keterangan :

$\mathrm{n}=$ Jumlah Populasi

$\mathrm{N}=$ jumlah Populasi

$\mathrm{d}=$ nilai presisi $85 \%$ atau $\operatorname{sig}=0,15$

Data populasi rata - rata pengunjung diambil dari 3 bulan terakhir yaitu Januari Maret 2019 sebesar 3494 orang/bulan, sehingga dapat diketahui responden pengunjung sebanyak 43 orang.

Pengukuran hasil responden dilakukan menggunakan Skala Likert. Tingkat persetujuan yang digunakan :

- Sangat Setuju (SS) diberi bobot 5

- Setuju (S) diberi bobot 4

- Netral (N) diberi bobot 3

- Tidak Setuju (TS) diberi bobot 2

- Sangat Tidak Setuju (STS) diberi bobot 1

$$
\operatorname{Indeks}(\%)=\frac{\text { Total skor }}{\text { Skor maksimum }} \times 100 \%
$$

Keterangan :

$\begin{array}{lll}\text { Indeks } 0 \%-19,99 \% & : & \text { Sangat Tidak Setuju } \\ \text { Indeks 20\%-39,99\% } & : & \text { Tidak Setuju } \\ \text { Indeks } 40 \%-59,99 \% & : & \text { Netral } \\ \text { Indeks } 60 \%-79,99 \% & : & \text { Setuju } \\ \text { Indeks } 80 \%-100 \% & : & \text { Sangat Setuju }\end{array}$

Faktor-faktor yang diteliti dalam penelitian ini adalah karakteristik potensi industri wisata di TWA Telaga Warna menggunakan Pedoman Analisis Wilayah Kerja Objek Wisata Alam dan Atraksi - ADO ODTWA (Dirjen PHKA, 2003). Hal-hal yang menjadi objek penilaian meliputi potensi pasar, keterbukaan, kondisi alam, eksekutif dan administrasi, lingkungan, kenyamanan, kerangka kerja dan kantor pendukung, aksesibilitas air bersih, hubungan dengan objek industri perjalanan lainnya, keamanan, 
batas penyampaian, rencana tamu, iklan dan bagian dari pasar dan pangsa pasar. Data yang sudah terkumpul dianalisis dengan kriteria penilaian ODTWA (Ginting et.al., 2015)

$$
S=N \times B
$$

Keterangan :

$$
\begin{array}{lll}
\mathrm{S} & : & \text { Skor/ Nilai suatu kriteria } \\
\mathrm{N} & : & \text { Jumlah nilai unsur-unsur } \\
\mathrm{B} & \text { : } & \text { Bobot nilai }
\end{array}
$$

Skor yang diperoleh dari setiap kriteria akan di tentukan tingkat kelayakanya menggunakan rumus interval yaitu:

$$
\text { Interval }=\frac{\text { Skor max }- \text { Skor min }}{\text { Banyaknya Klasifikasi }}
$$

Kategori Indeks kelayakan suatu kawasan obyek wisata alam:

- $\quad>66,6 \%$ (layak dikembangkan)

- $33,3 \%$ - 66,6\% (belum layak)

- $\quad<33,3 \%$ (tidak layak dikembangkan)

Tahap terakhir dalam penelitian ini adalah penggunaan Analisis Strength Weaknesses Oppurtunity Threat - SWOT (Rangkuti, 1997). Analisis SWOT dimulai dengan mengidentifikasi faktor-faktor internal dan eksternal yang dimiliki TWA Telaga Warna. Pemberian penilaian EFI dan EFE dilakukan dengan metode paired comparison

\begin{tabular}{|c|c|c|c|}
\hline Faktor Internal & Bobot & Rating & Skor \\
\hline \multirow{3}{*}{\multicolumn{4}{|c|}{$\begin{array}{l}\text { Strength } \\
1 . \\
2 .\end{array}$}} \\
\hline & & & \\
\hline & & & \\
\hline \multicolumn{4}{|l|}{ dst } \\
\hline \multicolumn{4}{|l|}{ Weakness } \\
\hline \multicolumn{4}{|l|}{1.} \\
\hline & & & \\
\hline dst & & & \\
\hline
\end{tabular}
(Kinnear, 1991).

Penilaian faktor internal dapat disusun seperti Tabel 1.

Tabel 1. Penilaian Faktor Internal

\begin{tabular}{|c|c|c|c|}
\hline Faktor Internal & Bobot & Rating & Skor \\
\hline \multicolumn{4}{|l|}{ Opportunity } \\
\hline \multicolumn{4}{|l|}{1.} \\
\hline \multicolumn{4}{|l|}{2.} \\
\hline dst & & & \\
\hline \multicolumn{4}{|l|}{ Threat } \\
\hline \multicolumn{4}{|l|}{1.} \\
\hline 2. & & & \\
\hline dst & & & \\
\hline
\end{tabular}

Penilaian faktor eksternal dapat disusun seperti tertera pada Tabel 2.

Tabel 2. Penilaian Faktor Eksternal

Pemahaman atas faktor-faktor tersebut menjadi dasar dalam penyusunan strategi terbaik dalam pengembangan TWA Telaga Warna (Tabel 3).

\begin{tabular}{lcc}
\multicolumn{3}{c}{ Tabel 3. Strategi Pengembangan TWA } \\
\hline \multicolumn{1}{c}{ Strategi } & Kekuatan & Kelemahan \\
& (Strength) & (Weakness) \\
\hline Peluang & Strategi & Strategi \\
(Opportunity) & SO & WO \\
Ancaman & Strategi & Strategi \\
(Threat) & ST & WT
\end{tabular}

Strategi yang sudah tersusun kemudian dianalisis berdasar posisinya terhadap kuadran SWOT (Gambar 1).

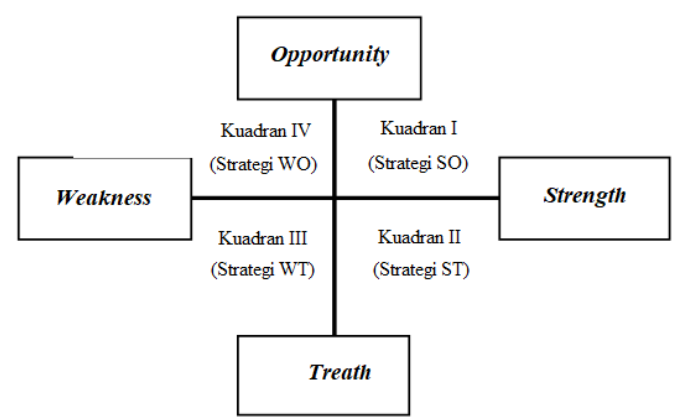

Gambar 1. Posisi Strategi Terpilih (Rangkuti, 1997)

\section{HASIL DAN PEMBAHASAN}

\section{Karakteristik dan Motivasi Pengunjung}

Pengunjung yang mengunjungi TWA Telaga Warna mayoritas dikunjungi laki-laki sebesar 67\%, umur 20-30 tahun sebesar 56\%, 
pendidikan SMA/SMK sebesar 93\%, pegawai swasta/ wiraswasta sebesar $84 \%$. Motivasi pengunjung mayoritas berkunjung adalah 1-3 kali sebesar $72 \%$, transportasi sepeda motor sebesar 70\%, biaya Rp. 100.000 - Rp. 250.000 sebesar $77 \%$, jarak > $30 \mathrm{~km}$ sebesar $53 \%$, waktu kunjungan 1-3 jam sebesar $72 \%$, melakukan kegiatan rekreasi sebesar $88 \%$ dan berkunjung bersama teman atau kolega sebesar $53 \%$.

\section{Karakteristik, Perpepsi dan Preferensi Masyarakat}

Masyarakat sekitar TWA Telaga Warna mayoritas laki-laki sebesar 53\%, umur 20 - 30 tahun sebesar $37 \%$, pendidikan tingkat SD sebesar $40 \%$ dan pekerjaan sebagai karyawan swasta sebesar $67 \%$. Persepsi sebanyak $100 \%$ hasil penelitian menyatakan bahwa sumberdaya alam di sekitar sangat potensial, mendukung dalam pengembangan wisata alam dan kondisi tanah yang subur di TWA Telaga Warna. Indeks preferensi masyarakat sebesar 79,90\% yang berarti setuju.

\section{Identifikasi Potensi ADO - ODTWA}

Data analisis kelayakan berdasarkan penilaian identifikasi potensi yang sudah mempunyai skor total. Skor total yang diperoleh kemudian dibandingkan dengan hasil interval, kemudian menentukan suatu kelayakan pada kriteria. Tingkat kelayakan menggunakan rumus interval (Ginting, et. al., 2015).

Hasil penilaian skor bobot kriteria dapat dilihat pada Tabel 4. Hasil penilaian skor total kriteria di TWA Telaga Warna sebesar 6.530. Penilaian hasil skor total suatu kriteria akan diperoleh indeks kelayakan ADO - ODTWA di TWA Telaga Warna. Indeks kelayakan dapat dilihat pada Tabel 5.
Tabel 4. Penilaian Skor Bobot Suatu Kriteria di TWA Telaga Warna

\begin{tabular}{|c|c|c|c|c|}
\hline No. & Kriteria & Bobot & Nilai & Skor \\
\hline 1 & Daya tarik & 6 & 210 & 1.260 \\
\hline 2 & Potensi pasar & 5 & 125 & 625 \\
\hline 3 & Aksesibilitas & 5 & 140 & 700 \\
\hline 4 & Kondisi sekitar kawasan & 5 & 165 & 825 \\
\hline 5 & $\begin{array}{l}\text { Pengelolaan dan } \\
\text { pelayanan }\end{array}$ & 4 & 85 & 340 \\
\hline 6 & Iklim & 4 & 45 & 180 \\
\hline 7 & Akomodasi & 3 & 30 & 90 \\
\hline 8 & $\begin{array}{l}\text { Sarana dan prasarana } \\
\text { penunjang }\end{array}$ & 3 & 55 & 165 \\
\hline 9 & Ketersediaan air bersih & 6 & 150 & 900 \\
\hline 10 & $\begin{array}{l}\text { Hubungan dengan } \\
\text { obyek wisata di } \\
\text { sekitarnya }\end{array}$ & 1 & 370 & 370 \\
\hline 11 & Keamanan & 5 & 80 & 400 \\
\hline 12 & Daya dukung kawasan & 3 & 85 & 255 \\
\hline 13 & $\begin{array}{l}\text { Penganturan } \\
\text { pengunjung }\end{array}$ & 3 & 25 & 75 \\
\hline 14 & Pemasaran & 4 & 30 & 120 \\
\hline 15 & $\begin{array}{l}\text { Pangsa pasar } \\
\text { Jumlah Total }\end{array}$ & 3 & 75 & $\begin{array}{c}225 \\
6.530\end{array}$ \\
\hline
\end{tabular}

Tabel 5. Indeks Kelayakan di TWA Telaga Warna

\begin{tabular}{|c|c|c|c|c|}
\hline No. & Kriteria & $\begin{array}{l}\text { Skor } \\
\text { Total }\end{array}$ & $\begin{array}{l}\text { Nilai } \\
\text { Maks }\end{array}$ & $\begin{array}{c}\text { Indeks } \\
(\%)\end{array}$ \\
\hline 1. & Daya tarik & 1.260 & 1.440 & 14,96 \\
\hline 2. & Potensi pasar & 625 & 650 & 7,42 \\
\hline 3. & Aksesibilitas & 700 & 800 & 8,31 \\
\hline 4. & $\begin{array}{l}\text { Kondisi sekitar } \\
\text { kawasan }\end{array}$ & 825 & 1.200 & 9,80 \\
\hline 5. & $\begin{array}{l}\text { Pengelolaan dan } \\
\text { pelayanan }\end{array}$ & 340 & 360 & 4,04 \\
\hline 6. & Iklim & 180 & 480 & 2,14 \\
\hline 7. & Akomodasi & 90 & 90 & 1,07 \\
\hline 8. & $\begin{array}{l}\text { Sarana dan } \\
\text { prasarana penunjang }\end{array}$ & 165 & 180 & 1,96 \\
\hline 9. & $\begin{array}{l}\text { Ketersediaan air } \\
\text { bersih }\end{array}$ & 900 & 900 & 10,69 \\
\hline 10. & $\begin{array}{l}\text { Hubungan dengan } \\
\text { obyek wisata di } \\
\text { sekitarnya }\end{array}$ & 370 & 790 & 4,39 \\
\hline 11. & Keamanan & 400 & 600 & 4,75 \\
\hline 12. & $\begin{array}{l}\text { Daya dukung } \\
\text { kawasan }\end{array}$ & 255 & 450 & 3,03 \\
\hline 13. & $\begin{array}{l}\text { Penganturan } \\
\text { pengunjung }\end{array}$ & 75 & 90 & 0,89 \\
\hline 14. & Pemasaran & 120 & 120 & 1,43 \\
\hline 15. & $\begin{array}{l}\text { Pangsa pasar } \\
\text { Jumlah }\end{array}$ & $\begin{array}{l}225 \\
6.530\end{array}$ & $\begin{array}{c}270 \\
8.420\end{array}$ & $\begin{array}{c}2,67 \\
77,55\end{array}$ \\
\hline
\end{tabular}

Sumber : Data Penelitian (2020) 
Indentifikasi potensi kelayakan di TWA Telaga Warna sebesar $77,55 \%$ yang berarti potensi kriteria ADO - ODTWA di TWA Telaga Warna, Kabupaten Bogor adalah layak dikembangkan.

\section{Identifikasi dan Penilaian Faktor-Faktor Internal dan Eksternal}

- Faktor-faktor internal dan eksternal TWA Telaga Warna yang diidentifikasi adalah :

- Daya tarik dan keindahan obyek wisata danau di TWA Telaga Warna sangat nyaman untuk dinikmati (S1)

- Sarana dan prasarana sudah ada pijakan awal dari pengembang wisata di TWA Telaga Warna (S2)

- Ketersedian air bersih di TWA Telaga Warna sangat berlimpah dan dapat dimanfaatkan oleh masyarakat sekitar (S3)

- Wahana atau atraksi yang ada mendukung di TWA Telaga Warna (S4)

- Tidak adanya keterbatasan pengunjung dalam pengaturan pengunjung lamanya untuk menikmati kenyamanan di TWA Telaga Warna (S5)

- Pengunjung yang berwisata di TWA Telaga Warna dapat dinikmati semua kalangan (S6)

- Pengelolaan dan pelayanan dalam manajemen pengembang wisata masih belum maksimal (W1)

- Jumlah Pegawai yang berkompenten atau bersertifikasi dalam keamanan belum signifikan (W2)

- Tarif yang tinggi, promosi masih belum terpublikasi dengan maksimal (W3)

- Jumlah penduduk Jawa Barat dan kebutuhan masyarakat terhadap wisata alam sangat tinggi (O1)

- Akses menuju tempat obyek wisata di TWA Telaga Warna sangat mudah dijangkau $(\mathrm{O} 2)$

- Banyak penginapan di daerah sekitar obyek wisata TWA Telaga Warna (O3)
- Wisata sejenis dan tidak sejenis di sekitar kawasan TWA Telaga Warna sangat potensial (T1)

- Sering terjadinya longsor di wilayah Puncak Bogor, dikarenakan curah hujan yang tinggi wilayah kabupaten bogor (T2)

- Persaingan dalam bisnis pariwisata disekitar TWA Telaga Warna sangat tinggi, baik yang sejenis maupun tidak sejenis (T3)

Identifikasi dan penilaian strategi faktor internal menghasilkan nilai sebesar 1,09 (Tabel 6). Sedangkan identifikasi dan penilaian strategi faktor eksternal menghasilkan nilai sebesar sebesar 0,60 (Tabel 7).

Tabel 6. Penilaian Faktor Internal TWA Telaga Warna

\begin{tabular}{cccc}
\hline $\begin{array}{c}\text { Faktor } \\
\text { Internal }\end{array}$ & Bobot & Rating & Skor \\
\hline Strength & & & \\
\hline S1 & 0,15 & 4 & 0,60 \\
S2 & 0,15 & 3 & 0,45 \\
S3 & 0,09 & 4 & 0,36 \\
S4 & 0,12 & 2 & 0,24 \\
S5 & 0,06 & 2 & 0,12 \\
S6 & 0,15 & 2 & 0,30 \\
\hline Sub Total & & & 2,07 \\
\hline Weakness & & & \\
\hline W1 & 0,11 & -4 & $-0,44$ \\
W2 & 0,10 & -3 & $-0,30$ \\
W3 & 0,08 & -3 & $-0,24$ \\
\hline Sub Total & & $-0,98$ \\
\hline Total & & 1,09 \\
\hline Sumber : Data Penelitian (2020)
\end{tabular}

Tabel 7. Penilaian Faktor Eksternal TWA Telaga Warna

\begin{tabular}{cccc}
\hline $\begin{array}{c}\text { Faktor } \\
\text { Eksternal }\end{array}$ & Bobot & Rating & Skor \\
\hline Opportunity & & & \\
\hline O1 & 0,20 & 2 & 0,40 \\
O2 & 0,20 & 3 & 0,60 \\
O3 & 0,16 & 4 & 0,64 \\
\hline Sub Total & & & 1,64 \\
\hline Treath & & \\
\hline T1 & 0,16 & -2 & $-0,32$ \\
T2 & 0,20 & -2 & $-0,40$ \\
T3 & 0,08 & -4 & $-0,32$ \\
\hline Sub Total & & $-1,04$ \\
\hline Total & & 0,60 \\
\hline Sumber : Data Penelitian $(2020)$ &
\end{tabular}




\section{Strategi Pengembangan}

Keterkaitan antara faktor internal dan eksternal di gambarkan dalam matrik SWOT. Alternatif yang diperoleh adalah strategi SO, ST, WO dan WT.

- Menjaga kelestarian daya tarik, keindahan dan ketersedian air TWA Telaga Warna, menjadi kepuasan pengunjung (SO)

- Membuat sarana prasarana agar pengunjung dapat menikmati panorama alam dan akses informasi yang mudah (SO)

- Membuat paket perjalanan wisata di TWA Telaga Warna dengan bekerjasama pihak hotel (SO)

- Rekruitmen pekerja sesuai kebutuhan (WO)

- Promosi dengan menyebarluaskan brosur ke hotel/ penginapan dan membuat spanduk (WO)

- Menata kawasan TWA Telaga Warna agar daya tariknya meningkat (ST)

- Berkordinasi dengan pihak pemerintahan setempat, kepolisian dan masyarakat dalam menjaga kawasan sekitar TWA Telaga Warna (ST)

- Membuat kreatifitas permainan/ atraksi yang berbeda dan unik (ST)

- Mengajak pemerintah dan masyarakat bersama-sama melakukan kegiatan promosi untuk pengembangan wisata TWA Telaga Warna (WT)

- Melakukan kegiatan pendidikan dan pelatihan secara professional dan bersertifikasi (WT)

\section{Penentuan Strategi Posisi Kuadran}

Berdasarkan hasil penilaian strategi EFI dan EFE di TWA Telaga Warna, maka disimpulkan pada penentuan posisi strategi koordinat $\mathrm{P}(1,09)$ dan $\mathrm{Q}(0,60)$. Hal ini TWA Telaga Warna pada posisi SO (Gambar 2).

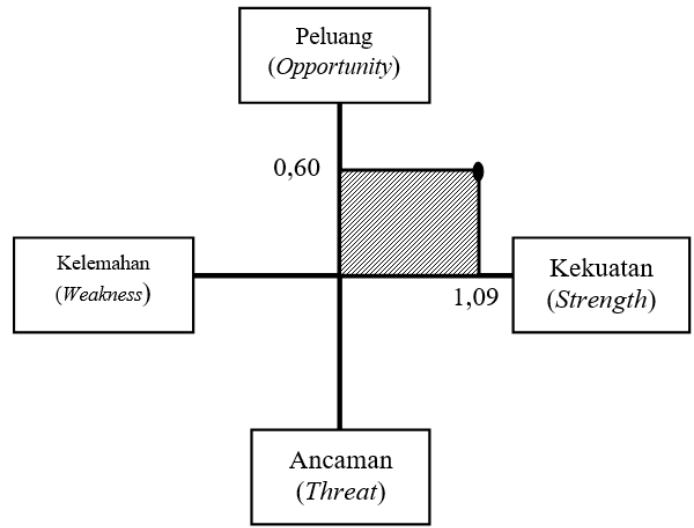

Gambar 2. Kuadran Strategi Pengembangan TWA Telaga Warna

\section{KESIMPULAN}

1. TWA Telaga warna memiliki potensi obyek wisata yang layak dikembangkan.

2. Strategi pengembangan TWA Telaga Warna yaitu dengan strategi SO yaitu memaksimalkan kekuatan (strength) yang dimiliki dan memaksimalkan peluang (opportunity).

\section{UCAPAN TERIMA KASIH}

Ucapan terima kasih disampaikan kepada Kepala Balai Besar KSDA Jawa Barat, Kepala Resort VII Cianjur, serta seluruh staf Balai Besar KSDA Jawa Barat atas dukungan dan kerjasama dalam kegiatan penelitian di TWA Telaga Warna.

\section{DAFTAR PUSTAKA}

Departemen Kehutanan, 2003. Pedoman Analisis Daerah Operasi Objek Daya Tarik Wisata Alam. Direktorat Wisata Alam dan Pemanfaatan Jasa Lingkungan. Direktorat Jenderal Perlindungan Hutan dan Konservasi Alam. Bogor: Departemen Kehutanan RI.

Kinnear TC. 1991. Marketing Research : an Applied Approach. Mc Grow Hill.

MacKinnon et. al. 1990. Dalam Ginting, I. A et. al. 2015. Penilaian dan Pengembangan Potensi Objek dan Daya Tarik Wisata Alam di Taman Wisata Alam (TWA) Sibolangit. Fakultas Pertanian. USU. Medan. 
Priyono. 2016. Metode Penelitian Kuantitatif. Zifatama. Edisi Pertama 2008. Edisi Revisi 2016. ISBN: 978-602-6930-31-6. Sidoarjo. Jawa Timur.

Rangkuti, F. 1997. Teknik Membedah Kasus Bisnis. Cetakan Keduabelas. PT. Gramedia Pustaka Utama. Jakarta.

Undang Undang RI Nomor 5 Tahun 1990 tentang Konservasi Sumber Daya Alam Hayati dan Ekosistemnya. Lembaran Negara RI Tahun 1990 No. 49. Jakarta, 10 Agustus 1990.

Undang-Undang RI Nomor 41 Tahun 1999 tentang Kehutanan. Lembaran Negara RI Tahun 1999 No. 167. Jakarta, 30 September 1999. 